\title{
Secondary Fluorescence Corrections for EPMA: PENELOPE MC Simulations
}

\author{
J. H. Fournelle, ${ }^{*}$ J. Gosses, ${ }^{*}$ J. Kelly, ${ }^{*}$ K. Staffier, ${ }^{*}$ J. Waters, ${ }^{* *}$ and C. Webber \\ * Department of Geology \& Geophysics, University of Wisconsin, Madison, WI 53706 \\ ** Department of Material Science \& Engineering, University of Wisconsin, Madison, WI 53706
}

Production of "stray" x-rays from phases at some distance from the primary electron impact zone and its associated electron scattering volume occurs in EPMA. This secondary fluorescence (SF) is a potential problem for several common sample types, i.e. diffusion couples, small phases enclosed in a larger phase, and eutectic intergrowths. In these cases, particularly where lower intensities of x-rays are assumed potentially to be present, as in diffusion profiles and in trace element measurements, the analyst may easily misinterpret the data acquired by the detector. Secondary fluorescence has been studied before experimentally [1]. In many cases this is difficult, expensive or impossible. The Monte Carlo simulation program PENELOPE presents the ability to evaluate the extent of SF [2]. This code uses ionization cross sections from optical data and bremsstrahlung cross sections that reproduce radiative stopping power derived from partial wave calculations. Llovet and co-workers have demonstrated the utility of PENELOPE for simulating SF in 3 situations: small $\mathrm{Cu}$ particles in Fe matrix, in Fe-Cu metal "dummy couples" and in $\mathrm{Ca}$ in olivine due to adjacent Ca-bearing minerals $[3,4]$. We present several other scenarios where SF is a problem, using PENELOPE.

$\mathrm{Nb}$ in $\mathrm{Pd}_{2} \mathrm{HfAl}$ [5]: This is the most extreme case. One lab found $\sim 10 \mathrm{wt} \% \mathrm{Nb}$ in $\mathrm{Pd}_{3} \mathrm{Hf}$ and $\mathrm{Pd}_{2} \mathrm{HfAl}$ in a eutectic assemblage, measuring $\mathrm{Nb} \mathrm{K \alpha}$ with $\mathrm{EDS}$ at $30 \mathrm{keV}$ (Fig 1). However, our WDS measurement of $\mathrm{Nb} L \alpha$ showed no $\mathrm{Nb}$ present, although we did see an $\mathrm{Nb} \mathrm{K} \alpha$ peak on our EDS display $\left(\mathrm{E}_{0}=28 \mathrm{keV}\right)$. Later WDS with an LIF220 crystal and a "dummy couple" of untreated $\mathrm{Nb} / \mathrm{Pd}_{2} \mathrm{HfAl}$ yielded an $\mathrm{Nb} \mathrm{K \alpha}$ pseudo-diffusion profile which we then modeled with PENELOPE (Fig 2). Our initial modeling was somewhat offset from the EPMA intensities, which led to the discovery that sample-detector geometry is important, i.e. if the fluoresced material faces the detector (solid angle larger), the counts are higher. When the experimental data was re-collected with this geometry, there was a close match to the PENELOPE simulated $\mathrm{Nb} \mathrm{K \alpha}$ intensities. All measured $\mathrm{Nb}$ in the eutectic phases can be explained by $\mathrm{SF}$ from $\mathrm{Nb}$ ss within $5 \mu \mathrm{m}$. This correction also resulted in a significant change in the eutectic phases' Pd contents due to changes in the ZAFs.

Ti and Al in quartz [6]: An EPMA study of trace levels of Al (100-200 ppm) and Ti (20-60 ppm) in quartz at $20 \mathrm{keV}$ [7] was evaluated by simulating SF of nearby $\mathrm{Al}_{2} \mathrm{O}_{3}$ and of $\mathrm{TiO}_{2}$ (which had not been considered in the study). It was found that the extent of secondary Al counts was insignificant $>10 \mu \mathrm{m}$ away, whereas SF Ti intensity at the $20 \mathrm{ppm}$ level was present out to $\sim 75 \mu \mathrm{m}$ away. Given that rutile inclusions are common in quartz, future EPMA studies need to rule out SF from rutile.

Fe in plagioclase [6]: EPMA analyses of plagioclase commonly contain several tenths of wt $\% \mathrm{Fe}$. Experimental studies [8,9] attempted to formulate a correction for SF, although the details are somewhat unclear. For An80 plagioclase adjacent to Fo90 olivine (at $15 \mathrm{keV}$ ), we found about 50\% more Fe than [8,9], e.g. $0.15 \mathrm{wt} \% \mathrm{FeO}$ at $20 \mu \mathrm{m}, 0.09 \mathrm{wt} \%$ at $40 \mu \mathrm{m}, 0.03 \mathrm{wt} \%$ at $100 \mu \mathrm{m}$.

$\mathrm{Ca}$ in orthopyroxene [6]: We evaluated the possible excess $\mathrm{Ca}$ in orthopyroxene exsolution lamallae due to SF from the host clinopyroxene, for its potential error in 2 pyroxene geothermometry for 
samples from Red Hills (New Zealand). The effect was found to be small: in a $5 \mu \mathrm{m}$ orthopyroxene exsolution lamella, $0.11 \mathrm{wt} \% \mathrm{Ca}$ was due to $\mathrm{SF}$, which translates to $\sim 10^{\circ} \mathrm{C}$ temperature difference (at $\sim 800^{\circ} \mathrm{C}$ ). At 50 microns, only $0.01 \mathrm{wt} \% \mathrm{Ca}$ was due to SF.

Al in $\mathrm{Mo}_{3} \mathrm{SiB}$ : The extent of $\mathrm{SF}$ of $\mathrm{Al}$ in $\mathrm{Mo}_{3} \mathrm{Al}_{8}$ coating on $\mathrm{Mo}_{3} \mathrm{SiB}$ substrate was modeled (in cross-section), to be able to correct EPMA measurements. At $5 \mu \mathrm{m}$ from the coating, there was an apparent $4.4 \mathrm{wt} \% \mathrm{Al}$, dropping to $0.9 \mathrm{wt} \%$ at $10 \mu \mathrm{m}, 0.4 \mathrm{wt} \%$ at $50 \mu \mathrm{m}, 0.2 \mathrm{wt} \%$ at $100 \mu \mathrm{m}$ and $0.006 \mathrm{wt} \%$ at $200 \mu \mathrm{m}$.

Meteorites: $\mathrm{Fe}$ in $\mathrm{Cu}$ [6]: PENELOPE showed that at $10 \mu \mathrm{m}$ from pure Fe there was $1.1 \mathrm{wt} \% \mathrm{Fe}$ due to SF, which decreased to $0.17 \mathrm{wt} \%$ at $30 \mu \mathrm{m}$ and $0.04 \mathrm{wt} \%$ at $50 \mu \mathrm{m}$. Fe in Ni: at $10 \mu \mathrm{m}$ from pure $\mathrm{Fe}, \mathrm{Ni}$ would have an apparent $1.1 \mathrm{wt} \% \mathrm{Fe}$, at $25 \mu \mathrm{m} 0.2 \mathrm{wt} \%$ and at $40 \mu \mathrm{m}, 0.07 \mathrm{wt} \% \mathrm{Fe}$.

Comments on PENELOPE: This software is coded in Fortran and runs from the terminal. Open source compilers are readily available. Input is via ascii files. The five co-authors are students in the UW-Madison EPMA class and learned how to set up and run the software on their computers with less than an hour of training. A new 2005 version offers many improvements [10].

References:

[1] S.J.B. Reed and J.V.P. Long, $3^{\text {rd }}$ Intl Symposium X-ray Optics \& X-ray Microanalysis (1962) 317.

[2] E. Acosta et al., J. Appl Phys 83 (1998) 6038.

[3] X. Llovet et al., Mikrochim Acta 132 (2000) 205.

[4] X. Llovet and G. Galan, Am. Mineral. 88 (2003) 121.

[5] J.H. Fournelle et al., sub to Surf \& Interf Anal (2005)

[6] J. Kelly et al, submitted to Goldschmidt 2005

[7] A. Muller et al., J Mineral. 15 (2003) 474.

[8] J. Longhi et al., Proc. Lun. Sci. Conf 7 (1976) 1281.

[9] T. Sugawara, Jap. Mag. Min. Pet. Sci.30 (2001) 159.

[10] We acknowledge invaluable assistance of Francesc

Salvat and Xavier Llovet.

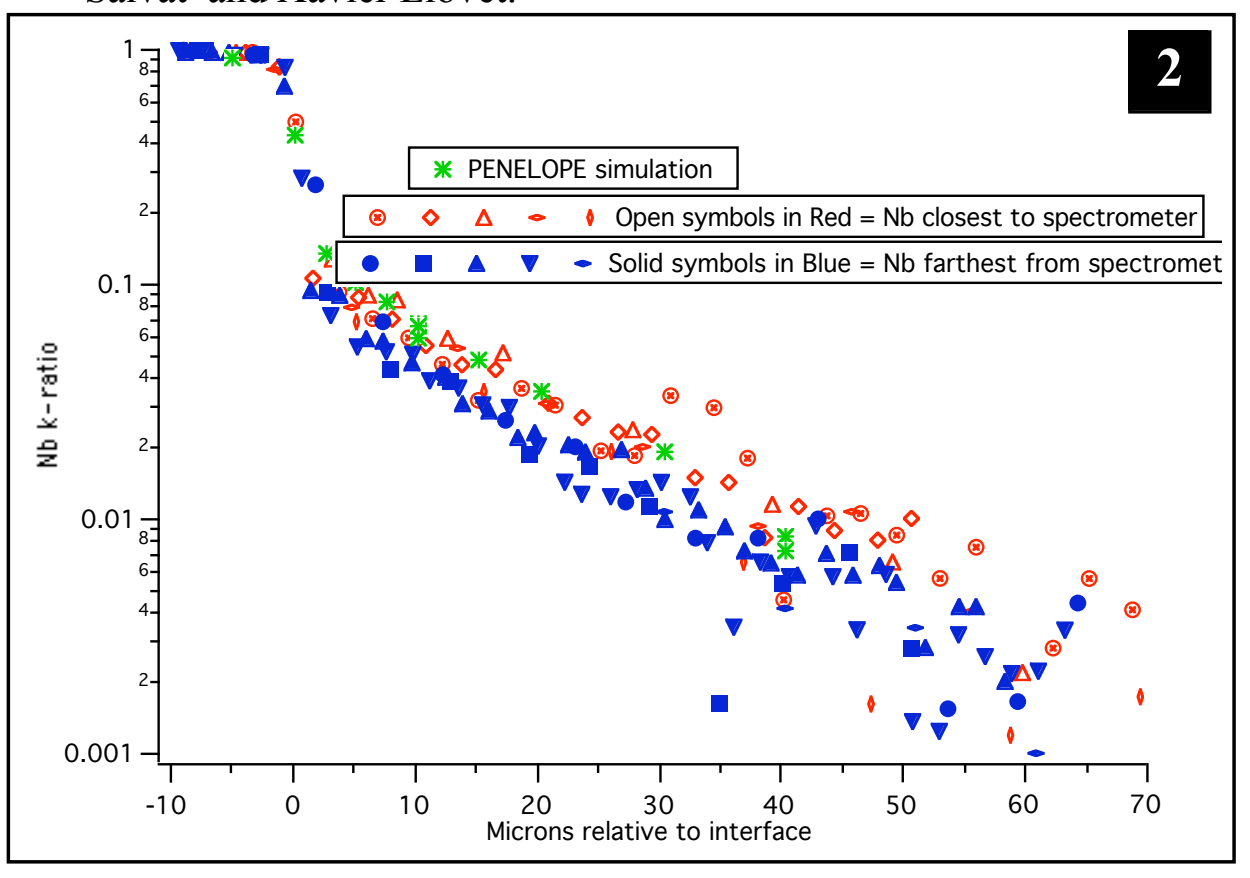

FIG. 1 BSE image of annealed eutectic sample. Note the close proximity of the $\mathrm{Nb}$ ss to the $\mathrm{Pd}_{3} \mathrm{Hf}$ and matrix $\mathrm{Pd}_{2} \mathrm{HfAl}$.

FIG 2. Experimental WDS $\mathrm{Nb}$ Ka K-ratio data $(28 \mathrm{keV})$ acquired with SX51 with LIF220. Open symbols are for $\mathrm{Nb}$ facing (closest to) spectrometer; solid symbols for $\mathrm{Nb}$ away from spectrometer (interface of dummy couple @ $90^{\circ}$ to spectrometer. PENELOPE simulations closely match the first symbols. $\mathrm{Y}$ axis $=\mathrm{Nb} \mathrm{K} \alpha \mathrm{K}$ ratio 